\title{
Dysbiosis in Alzheimer's disease might be triggered by certain classes of antibiotics with time-lapse: New insights in the pathogenesis?
}

\author{
Gábor Ternák MD, PhD 1., Márton Németh MD, PhD 2., Martin Rozanovic MD 2, Lajos \\ Bogár MD, DSc 2.
}

1. University of Pécs, Medical School, Institute of Migration Health, Pécs, Szigeti st. 12., H7624 Hungary

2. University of Pécs, Medical School, Department of Anesthesiology and Intensive Care, Pécs, Szigeti st. 12., H-7624 Hungary

Correspondence: should be addressed to Gábor Ternák e-mail: gabor.ternak@aok.pte.hu

Marton Nemeth e-mail: nemethmarton85@gmail.com

Martin Rozanovic e-mail: Rozanovic.martin@gmail.com

Lajos Bogár e-mail: bogar29@t-online.hu

Keywords: antibiotic consumption; gut flora; dysbiosis; Alzheimer disease; dementia; gut-brain axis, mediator molecules

\begin{abstract}
Background and objectives: Alzheimer's disease (AD) is a progressive neurodegenerative illness, responsible for $60-70 \%$ of all dementias, affecting over 50 million people worldwide, and nearly 11 million in European countries. Several putative factors are identified in the literature as causative agents or risk factors for the development of $\mathrm{AD}$. The amyloid cascade hypothesis has been the main hypothesis about the pathophysiology of AD for decades. Recent studies raised the possible role of dysbiosis in the development of AD which prevents memory loss. The amyloid- $\beta(A \beta)$ deposition might be considered as an inflammatory reaction to certain molecular products arising from the altered microbiome. Based on the above observations, it has been suspected, that antibiotic consumption patterns of different antibiotic classes might be associated with the prevalence of AD in European countries.
\end{abstract}

Methods: Antibiotic consumption (ECDC) for 1997-2007, 2008-2018, and as the whole 19972018 period, have been compared to the AD prevalence for 2018 expressed in percentage of the population and statistically analyzed by Pearson calculation.

Results: A significant positive correlation has been found between the AD prevalence (2018) and the average quinolone consumption for the year 1997-2007 ( $p: 0.044)$. A similar association was not observed for the entire 22 years (1997-2018) of the average quinolone consumption, and the years 2008-18, indicating 10-20 years of time-lapse between the antibiotic exposure and the development of $\mathrm{AD}$. The ratio of broad-spectrum and narrow-spectrum antibiotics $(\mathrm{B} / \mathrm{N})$ estimated in the ECDC database for the years of 2008-2018 showed a strong positive association with AD prevalence (2018) ( $p: 0.026$ ) and a positive correlation tendency for the entire 22 years 1997-2018 ( $p: 0.063$ ), but none for the years 1997-2007 ( $p: 0.241$ ). Broadspectrum, beta-lactamase sensitive penicillin (J01CA) consumption showed a positive (nonsignificant) correlation with the prevalence of AD for the years 2008-2018 ( $p: 0.080$ ).

Discussion: Our study indicated the possible sequential role of certain classes of antibiotics in the development of dysbiosis leading to amyloid deposits of $\mathrm{AD}$, which strengthen the possible role of different mediator molecules (short-chain fatty acids, lipopolysaccharides, etc.) produced by the altered microbiome in the development of AD.

\section{Introduction}


Diagnosed by the German psychiatrist and neuropathologist, Aloise Alzheimer in 1906, Alzheimer's disease (AD) is the most prevalent form of dementia in the aging population ${ }^{1}$. AD is considered the sixth major cause of death in the USA (Alzheimer's: America's Sixth Leading Cause of Death)). AD patients exhibit the gradual decline of cognitive abilities and memory functions until the development of incapability to perform routine daily functions ${ }^{2,3}$. The number of prevalent cases of dementia doubled from 1990 to 2016, while the age-standardized data of population aging and growth remained about the same. According to the 2016 Global Burden of Diseases (GBD) data, the prevalence of Alzheimer's disease in Europe stands at $5.05 \%$. Regarding all cases, the prevalence was about half in men compared to women $(3.31 \%$ vs. 7.13\%). The number of newly diagnosed AD patients in Europe was 11.08 per 1000 personyears ${ }^{3,4,5}$. According to the WHO report (September 2020), around 50 million people have dementia, and there are nearly 10 million new cases every year. Alzheimer's disease is the most common form of dementia and may contribute to $60-70 \%$ of the cases ${ }^{6,7}$.

In the early ' $90 \mathrm{~s}$, the amyloid cascade hypothesis has been the main hypothesis about the pathophysiology of $\mathrm{AD}^{8,9}$.

The putative etiologies and risk factors are extensively reported in the relevant publications ${ }^{10}$. Recent studies ${ }^{11-13}$ raised the possible role of dysbiosis in the development of AD, and antibiotics entering the human body, either as therapeutic agents or as environmental pollutants, considered strong agents capable of modifying the gut microbial flora. Now, it is suspected that the development of AD starts, with dysbiosis and inflammatory changes in the gut, 10-20 (30) years before the actual development of AD, involving different mechanisms, primarily mediator molecules, (gut-brain axis /GBA/) produced by the intestinal microbiome. It is more likely that infections, infectious agents, and their toxic products may be a trigger factor for neurodegenerative processes, mainly through the disruption of the functioning of the immune system, which is associated with excessive synthesis and accumulation of $A \beta$, hyperphosphorylation of tau protein, and induction of chronic inflammation in the brain ${ }^{14,15}$.

Intestinal microflora, which contains up to $95 \%$ of all human microbiome bacteria, forms the microbiome-gut axis that provides two-way communication through cytokine, immunological, hormonal, and neuronal signals ${ }^{16,17}$.

\section{Hypothesis/objectives}

The possible role of dysbiosis in the development of $\mathrm{AD}$ raises the concept that external factors, including antibiotics, might trigger this process. Antibiotics are one of the most powerful agents triggering profound changes in the composition of gut flora, particularly early in life, when the gut microbiota has not yet been fully established, and hence, they might contribute to the development of dysbiosis. Dysbiosis might contribute to the pathomechanisms of different metabolic, neurodegenerative, and other diseases ${ }^{18-22}$ including AD.

As far as different classes of antibiotics might trigger different dysbiosis, including the ones promoting $\mathrm{AD}$, we have hypothesized that the $\mathrm{AD}$-associated dysbiosis might be related to the qualitative and quantitative consumption of different classes of antibiotics and reflected in the prevalence figures of $\mathrm{AD}$ in European countries. The higher consumption rate of certain classes of antibiotics, through the modification of gut flora, might be responsible for the higher prevalence of $\mathrm{AD}$.

To evaluate the relevance of our hypothesis, we have compared the average yearly antibiotic consumption data of different European countries to the calculated prevalence of AD published as a percentage of the population in European countries, in the Dementia Yearbook of 2020 for $2018^{7}$.

\section{Methods}


Based on the ECDC yearly reports of antibiotic consumption ${ }^{23}$ in the community from 1997 to 2018 (22 years) at ATC (Anatomical Therapeutic Chemical classification) level three and level four in the group of J01C (penicillin), average yearly antibiotic consumption was calculated for 30 European countries. The average total yearly systemic antibiotic consumption (J01) was expressed in Defined Daily Dose/1,000 inhabitants/day (DID) and the relative share of major antibiotic groups (J01A /tetracycline/). J01C /penicillin/. J01D /cephalosporin/. J01F /macrolide/. J01M /quinolone/) in DID was calculated as a percentage of the total (J01) consumption. At ATC level four of the penicillin group consumption (J01CE /narrow spectrum, beta-lactamase sensitive penicillin/, J01CF /narrow spectrum, beta-lactamase resistant penicillin/, J01CA /broad-spectrum, beta-lactamase resistant penicillin/, and J01CR /broad-spectrum, beta-lactamase resistant combination penicillin/) was estimated as yearly average consumption in the years 1997-2018. Concerning the long process of the development of $\mathrm{AD}$, we have suspected that the role of antibiotic consumption, if such association exists, does not follow immediately the increase of AD prevalence, but several years later. Testing the relevance of this hypothesis, we have calculated the average yearly antibiotic consumption separately for the years 1997-2007 and 2008-2018.

Prevalence data of AD was obtained from the Dementia in Europe Yearbook $2020^{7}$ and appeared as a percentage of the population. Pearson correlation was used to calculate significance.

A strong correlation was considered when $p$ values were $\leq 0.05$. The data for comparisons are shown in Tables 1-3. Scatter diagrams showed the association between the quinolone (J01M), broad-spectrum, beta-lactamase sensitive penicillin (J01CA), and the broad spectrum/betalactamase inhibitor combination penicillin (J01CR) consumption and the prevalence of AD 2018. Similarly, diagrams were plotted to compare the ratio of broad-spectrum and narrowspectrum $(\mathrm{B} / \mathrm{N})$ antibiotics to $\mathrm{AD}$ prevalence (Diagrams 1-5.).

Standard Protocol Approvals, Registrations, and Patient Consents:

Publicly available, already published, statistical data of antibiotic consumption (ECDC), and the prevalence of AD (Dementia Yearbook) had been compared and statistically analyzed, which did not require any ethical approval. The study did not contain any patient data, and no patient's consent was requested.

\section{Results}

Using Pearson calculation, a strong positive correlation has been found between the AD prevalence (2018) and the average quinolone consumption for the year 1997-2007 (Pearson $p$ : 0.044). We did not find a similar association for the entire 22 years (1997-2018), and the average quinolone consumption for 2008-18 and the prevalence of AD, indicating 10-20 years of time-lapse between the antibiotic exposure (quinolone) and the development of AD. The ratio of broad-spectrum and narrow-spectrum antibiotics (B/N) estimated in the ECDC database for the years of 2008-2018 showed a strong positive association with AD prevalence (2018) ( $p: 0.026)$ and a positive correlation tendency for the entire 22 years of 1997-2018 ( $p: 0.063$ ), but none for the years 1997-2007 ( $p: 0.241)$. Broad-spectrum, beta-lactamase sensitive penicillin (J01CA) demonstrated positive, moderate ( $p: 0.08$ ), correlation tendencies for 200818 (shown in Table 3, and Diagram 4.) also. Interestingly, no similar association has been observed on comparing broad-spectrum, beta-lactamase combined (J01CR) penicillin and the prevalence of $\mathrm{AD}$ (Diagram 5.).

\section{Discussion}


The microbial community of the gut includes trillions of bacteria with an estimated biomass of $1.5-2 \mathrm{~kg}$ and this is the largest organ in the body composed of 1,000-1,200 cell types (species) that encode 150- fold more genes (microbiome) than we have in our genome. The gut microbiota plays a fundamental role in human health, as it evolved specific functions that complement human metabolism and physiology, and several external factors are capable of influencing its composition, reducing the diversity of the microbiome, and paving the way for different diseases ${ }^{24,25}$.

Antibiotics are considered the most effective external factors producing perturbance of the microbial flora. Common features of post-antibiotic dysbiosis include a loss of taxonomic and functional diversity combined with reduced colonization resistance against invading pathogens, which harbors the danger of antimicrobial resistance ${ }^{26}$.

Many studies reported a decrease in bacterial diversity with antibiotic treatment. An extensive meta-analysis including 129 studies indicated that amoxicillin, cephalosporin, macrolides, clindamycin, quinolones, and sulphonamides decreased the abundance of $E$. coli in the gut flora. Even the short-term effect of broad-spectrum antibiotics on the gut flora was profound, with a loss of diversity and drastic shifts in community composition. In addition, antibiotics considerably reduced the abundance of bacterial taxa with important metabolic functions, such as the production of butyrate and other molecules ${ }^{27}$. Experimental studies using the most frequently prescribed quinolone, ciprofloxacin (CPFX), indicated that high CPFX treatment impaired tight junction molecules $O c \ln / Z O-1$ level and down-regulated antibacterial genes expression (reg $3 \gamma$, pla2g $2 \alpha$, and defbl). Further, the high CPFX treatment increased proinflammatory cytokine IL- $1 \beta$ in the intestinal tract decreased $I L-17 A$ of the duodenum but increased $I L-17 A$ of the colon at day $37^{28}$.

Enteric bacteria may have a major impact on the immune system, brain development, and behavior, as they can produce several neurotransmitters and neuromodulators like serotonin, kynurenine, catecholamine, etc., as well as amyloids. However, brain destructive mechanisms, that can lead to dementia and $\mathrm{AD}$, start with the intestinal microbiome dysbiosis, development of local and systemic inflammation, and dysregulation of the GBA. Increased permeability of the gut epithelial barrier results in an invasion of different bacteria, viruses, and their neuroactive products that support neuroinflammatory reactions in the brain ${ }^{14}$. The alteration of the microbiome in AD had been reported, indicating the increased Bacteroides and decreased Bifidobacterium presence in the fecal samples of AD patients, and they observed correlations between levels of differentially abundant gut microbiota and cerebrospinal fluid (CSF) biomarkers of AD pathology also ${ }^{29}$.

Microbial amyloids or LPS can activate toll-like receptors (TLRs) in the gut, leading to the release of pro-inflammatory and/or anti-inflammatory cytokines, which results in the imbalance of the immune system, contributing to the progression of $\mathrm{AD}$ pathologies and cognitive decline ${ }^{30}$.

The AD is mostly sporadical, and no appropriate causative factors identified yet. The genetic background might be responsible only for $1-5 \%$ of the cases and is considered as familial AD 2,31 . Other possible causes of AD are mentioned in the literature ${ }^{2,3,32-34}$. The hypothesis that AD may be associated with specific dysbiosis of microbes in the intestine is observed in animal models also ${ }^{35}$. In studies with so-called germ-free rodents, a characteristic reduction of the A $\beta$ pathology was observed, which came back again when the mice were exposed to the gut microbiota of the control mice ${ }^{35}$.

Even though the amyloid- $\beta(\mathrm{A} \beta)$ is still considered as the most important causative agent of $\mathrm{AD}$, the failures of $\mathrm{A} \beta$-centric therapies call for different therapeutic approaches. Neuroinflammation is considered a possible driving force of neurodegeneration ${ }^{36}$. Microglia plays a crucial role in maintaining the homeostasis of brain tissue and secreting different 
neurotrophic factors, cytokines, chemokines, etc. after infection and cell injury, which triggers inflammatory changes and immune response followed by tissue repair ${ }^{37}$.

Large meta-analyses have confirmed the presence of elevated pro-inflammatory cytokines (PICs) and other inflammatory molecules in the serum and whole blood of AD patients, indicating a higher inflammatory status, evidenced by elevated levels of interleukin 6(IL-6), IL-12, tumor necrosis factor-alpha (TNF- $\alpha$ ), IL-1 $\beta$ and IL-18, etc., compared with age- and sex-matched healthy controls $^{38-40}$.

Studies in acute and chronic animal models of AD showed a possible beneficial effect of doxycycline $^{41}$. In the case of the animal model investigating the effects of short-term doxycycline therapy, memory recovery was also demonstrated ${ }^{42}$. According to a new concept, antimicrobial protection can be another important factor in the development of AD. Even rifampicin exhibited certain "brain-protective" properties ${ }^{43,44}$. This theory emphasizes that the accumulation of $A \beta$ in the brain is only an epiphenomenon that represents the immune response to the accumulation of harmful bacteria. The key point of this theory is that $A \beta$ peptide "represents a natural antimicrobial agent", however during the development of the AD A $\beta$ accumulates in the brain due to a constant inflammation caused by the microbiome of the gut.

The classical amyloid cascade model for Alzheimer's disease (AD) has been challenged by several findings and accumulating evidence proves the possibility that $\mathrm{AD}$ starts in the intestine (dysbiosis). Molecular pathomechanisms leading to augmented inflammatory process associated with the development of amyloid and tau pathology, mitochondrial dysfunction, etc. are reported in the literature $^{45}$. Microbiome-derived proteins, lipoproteins, and nucleic acids provide essential microorganism-specific gene products which support microbial structure, function, and viability. Many of these are the same components shed from the different Gram-negative bacterial species into surrounding bio-fluids, which eventually enter thesystemic circulation ${ }^{46}$. The abundance of short-chain fatty acids (SCFAs), is often low in the gut of older adults with $\mathrm{AD}$. It has been demonstrated that inhibition of free fatty acid receptor 2 (FFAR2) signaling increases amyloid-beta $(\mathrm{A} \beta)$ stimulated neuronal toxicity ${ }^{47}$.

Our analyses support the probability that antibiotic-modified microbiome might play part in the development of $\mathrm{AD}$ in addition to other putative factors. It is important to note that this effect might develop 10-15-(20) years later after the suspected initial antibiotic exposure and microbiome modification (dysbiosis) possibly triggering a self-perpetual, slow-motion chain of molecular mechanisms ending up in $\mathrm{AD}$ and other dementias.

We have found that the average quinolone (J01M) consumption for the years 1997-2007 in the countries included in the study, showed a remarkable positive association with the prevalence of AD (and other dementias) estimated for 2018, indicating an about 10-year lapse between the antibiotic insult and the development of AD. Our comparative study identified certain classes of antibiotics (quinolone $/ \mathrm{J} 01 \mathrm{M} /$, and broad-spectrum, betalactamase sensitive penicillin $/ \mathrm{J} 01 \mathrm{CA} /$ ), which might alter the microbiome in a favorable way for the development of $\mathrm{AD}$, while broad-spectrum, combination penicillin did not show a similar association, indicating the possible ameliorating effect of beta-lactamase inhibitors in the development of AD. This effect might appear in a sequential pattern indicating the possible time lapse between the antibiotic insult and the development of AD. The cumulative effect of broad-spectrum antibiotics might enhance the development of AD also.

The limitation of our study is that the role of antibiotic consumption patterns cannot be observed at the individual level for AD patients compared to a control group.

We assume that different antibiotics might induce different changes in the composition of the gut microbiome, which alters the production of different mediator molecules influencing the development of different diseases, including AD. (Figure 1.). 


\begin{tabular}{|c|c|c|c|c|c|c|c|c|c|c|c|c|}
\hline $\begin{array}{l}\text { Average. yearly } \\
\text { antibiotic } \\
\text { consumption } \\
\text { ECDC 1997- } \\
2018 \\
\end{array}$ & $\begin{array}{c}\text { Defined Daily } \\
\text { Dose/ 1000 } \\
\text { inhabitants/ } \\
\text { day (100\%) } \\
\text { J01 } \\
\end{array}$ & $\begin{array}{c}\text { J01A } \\
\%\end{array}$ & $\begin{array}{c}\mathrm{J01C} \\
\%\end{array}$ & $\begin{array}{c}\text { J01CA } \\
\%\end{array}$ & $\begin{array}{c}\text { J01CR } \\
\%\end{array}$ & $\begin{array}{c}\text { J01CE } \\
\%\end{array}$ & $\begin{array}{c}\text { J01CF } \\
\%\end{array}$ & $\begin{array}{c}\text { J01D } \\
\%\end{array}$ & $\begin{array}{c}\mathrm{J01F} \\
\%\end{array}$ & $\begin{array}{c}\mathrm{J01M} \\
\%\end{array}$ & $\begin{array}{c}\text { Average consumption } \\
\text { ratio of broad and } \\
\text { narrow-spectrum } \\
\text { antibiotics }(\mathrm{B} / \mathrm{N}) 1997 \text { - } \\
2018 \\
\end{array}$ & $\begin{array}{c}\text { Prevalence of } \\
\text { AD and other } \\
\text { dementias in \% } \\
\text { of the } \\
\text { population } 2018 \\
\end{array}$ \\
\hline Austria & 12.12 & 9.21 & 35.74 & 6.92 & 20.7 & 8.23 & 0.07 & 13.14 & 26.71 & 11.55 & 5.39 & 1.66 \\
\hline Belgium & 21.96 & 11.33 & 40.07 & 17.3 & 21.03 & 0.44 & 1.17 & 11.12 & 14.63 & 10.79 & 42.8 & 1.69 \\
\hline Bulgaria & 17.39 & 13.34 & 37.45 & 23.45 & 9 & 5.06 & 0.09 & 14.71 & 14.28 & 11.18 & 11.84 & 1.54 \\
\hline Croatia & 18.59 & 7.9 & 42.19 & 13.58 & 22.7 & 5.73 & 0.16 & 17.72 & 15.06 & 8.35 & 5.06 & 1.6 \\
\hline Cyprus & 26.95 & 11.76 & 35.17 & 11.34 & 23.58 & 0.34 & 0.09 & 21.53 & 11.61 & 16.27 & 26.36 & 1.17 \\
\hline Czech Rep. & 15.01 & 15.12 & 36.71 & 6.66 & 13.03 & 12.76 & 0.43 & 8.29 & 19.89 & 7.35 & 3.14 & 1.41 \\
\hline Denmark & 14.18 & 9.84 & 62.59 & 19.01 & 2.51 & 33.53 & 7.5 & 0.2 & 14.9 & 3.37 & 0.36 & 1.51 \\
\hline Estonia & 10.41 & 20.8 & 32.88 & 20.29 & 9 & 2.44 & 0.06 & 9.42 & 19.39 & 8.07 & 7.55 & 1.74 \\
\hline Finland & 16.79 & 23.89 & 29.75 & 15.87 & 4.5 & 9.23 & 0.39 & 13.85 & 10.35 & 5.31 & 0.6 & 1.74 \\
\hline France & 24.88 & 13.04 & 44.13 & 26.85 & 15.74 & 0.72 & 1.46 & 11.36 & 16.61 & 7.87 & 25.58 & 1.83 \\
\hline Germany & 12.9 & 20.99 & 27.39 & 16.65 & 2.38 & 8.5 & 0.11 & 16.82 & 19.02 & 9.94 & 3.4 & 1.91 \\
\hline Greece & 30.42 & 8.26 & 27.81 & 13.44 & 12.79 & 1.62 & 0.01 & 24.59 & 27.75 & 8.92 & 126.73 & 1.99 \\
\hline Hungary & 14.96 & 10.68 & 35.96 & 10.26 & 21.1 & 4.59 & 0 & 14.28 & 20.77 & 12.63 & 20.85 & 1.49 \\
\hline Iceland & 19.47 & 25.46 & 48.23 & 17.47 & 11.58 & 12.99 & 5.95 & 2.57 & 8.19 & 4.19 & 1.11 & 1.15 \\
\hline Ireland & 18.25 & 2.8 & 44.98 & 14.84 & 18.88 & 5.05 & 5.98 & 8.49 & 18.9 & 5.01 & 4.06 & 1.09 \\
\hline Italy & 22.01 & 10.65 & 42.44 & 16.45 & 25.53 & 0.05 & 0.07 & 12.69 & 21.78 & 14.75 & 97.27 & 2.12 \\
\hline Latvia & 10.58 & 22.15 & 38.1 & 26.4 & 10.9 & 0.93 & 0.02 & 4.87 & 13.1 & 9.5 & 7.85 & 1.74 \\
\hline Lithuania & 15.88 & 10.6 & 48.14 & 31.75 & 8.46 & 7.63 & 0.41 & 9 & 12.04 & 6.74 & 6.28 & 1.74 \\
\hline Luxembourg & 23.01 & 9.94 & 34.97 & 13.42 & 20.04 & 0.42 & 0.87 & 18.62 & 18.17 & 10.96 & 25.58 & 1.25 \\
\hline Malta & 18.83 & 6.53 & 33.5 & 3.15 & 30.26 & 0.39 & 0.27 & 23.24 & 20.58 & 11.55 & 111.18 & 1.38 \\
\hline Netherlands & 9.34 & 25.57 & 32.12 & 13.72 & 10.44 & 4.06 & 3.65 & 0.6 & 14.74 & 9.18 & 5.69 & 1.49 \\
\hline Norway & 15.29 & 19.38 & 40.57 & 12.83 & 0 & 24.16 & 3.42 & 1.01 & 10.92 & 3.42 & 0.17 & 1.41 \\
\hline Poland & 18.77 & 14.46 & 33.7 & 20.94 & 12.03 & 2.21 & 0.11 & 12.78 & 18.23 & 6.82 & 19.72 & 1.38 \\
\hline Portugal & 18.34 & 5.74 & 42.35 & 11.9 & 27.67 & 0.16 & 3.21 & 12.67 & 17.48 & 14.25 & 20.26 & 1.88 \\
\hline Romania & 24.14 & 4.1 & 47.17 & 18.12 & 23.19 & 3.1 & 2.6 & 19.03 & 11.5 & 13.06 & 10.64 & 1.43 \\
\hline Slovakia & 21.52 & 8.56 & 39.41 & 10.5 & 15.14 & 13.46 & 0.08 & 16.87 & 22.06 & 8.93 & 5.53 & 1.15 \\
\hline Slovenia & 13.19 & 4.06 & 55.39 & 16.6 & 21.78 & 15.66 & 1.1 & 3.83 & 19.39 & 9.89 & 2.74 & 1.65 \\
\hline Spain & 17.26 & 5.79 & 51.11 & 20.62 & 28.44 & 0.58 & 1.28 & 11.25 & 14.69 & 13.8 & 39.34 & 1.83 \\
\hline Sweden & 13.8 & 22.01 & 47.45 & 7.59 & 1.3 & 28.68 & 9.53 & 2.32 & 5.5 & 6.23 & 0.16 & 1.66 \\
\hline UK & 15.26 & 25.78 & 38.4 & 21.37 & 4.95 & 4.86 & 7.15 & 3.96 & 17.3 & 3.62 & 0.94 & 1.56 \\
\hline Pearson $R$ & $-\mathbf{- 0 . 0 7 7}$ & 0.039 & -0.068 & 0.293 & -0.016 & -0.183 & -0.232 & 0.042 & 0.202 & 0.230 & $\underline{0.344}$ & \\
\hline Pearson $P$ & 0.689 & 0.839 & 0.719 & 0.117 & 0.435 & 0.334 & 0.219 & 0.824 & 0.286 & 0.331 & $\underline{0.063}$ & \\
\hline
\end{tabular}

Table 1. Yearly, average antibiotic consumption for 1997-2018 expressed in percentage (\%) of the total, systemic antibiotic consumption (J01, 100\%) estimated as Defined Daily Dose/ 1000 inhabitants/ Day (DID) per country. ATC codes: J01A: tetracycline, J01C: penicillin, J01CA: broad-spectrum, beta-lactamase sensitive penicillin, J01CR: broad-spectrum, betalactamase sensitive penicillin combined with beta-lactamase inhibitors, J01CE: narrow spectrum, penicillinase sensitive penicillin, J01CF: narrow spectrum, beta-lactamase resistant penicillin, J01D: cephalosporin, J01F: macrolide, J01M: quinolone, J01 B/N: the ratio of the broad and narrow-spectrum antibiotics.

A positive correlation tendency was observed between the ratios (consumption) of broad/narrow-spectrum antibiotics and AD prevalence ( $p: 0.063)$. 


\begin{tabular}{|c|c|c|c|c|c|c|c|c|c|c|c|c|}
\hline $\begin{array}{l}\text { Average. yearly } \\
\text { antibiotic } \\
\text { consumption } \\
\text { ECDC 1997-2007 }\end{array}$ & $\begin{array}{l}\text { 100\% } \\
\text { J01 }\end{array}$ & $\begin{array}{l}\text { J01A } \\
\%\end{array}$ & $\begin{array}{l}\text { J01C } \\
\%\end{array}$ & $\begin{array}{l}\text { J01CA } \\
\%\end{array}$ & $\begin{array}{l}\text { J01CR } \\
\%\end{array}$ & $\begin{array}{l}\text { J01CE } \\
\%\end{array}$ & $\begin{array}{l}\text { J01CF } \\
\%\end{array}$ & $\begin{array}{l}\text { J01D } \\
\%\end{array}$ & $\begin{array}{l}\text { J01F } \\
\%\end{array}$ & $\begin{array}{l}\text { J01M } \\
\%\end{array}$ & $\begin{array}{l}\text { Average B/N } \\
1997-2007\end{array}$ & $\begin{array}{l}\text { Prevalence of AD and } \\
\text { other dementias in } \% \\
\text { of the population } \\
2018\end{array}$ \\
\hline Austria & 11.76 & 10.42 & 32.40 & 7.26 & 15.10 & 9.94 & 0.09 & 13.36 & 9.94 & 12.96 & 4.09 & 1.66 \\
\hline Belgium & 21.35 & 13.93 & 33.07 & 12.69 & 18.44 & 0.72 & 1.21 & 16.32 & 0.72 & 10.91 & 17.40 & 1.69 \\
\hline Bulgaria & 17.20 & 17.65 & 44.44 & 28.66 & 5.82 & 9.68 & 2.13 & 10.73 & 9.68 & 7.38 & 1.25 & 1.54 \\
\hline Croatia & 19.74 & 4.31 & 41.61 & 16.22 & 17.36 & 7.74 & 0.33 & 18.40 & 7.74 & 8.67 & 2.14 & 1.6 \\
\hline Cyprus & 27.90 & 10.07 & 36.38 & 16.42 & 19.53 & 0.43 & 0.01 & 23.76 & 0.43 & 13.62 & 16.28 & 1.17 \\
\hline Czech Republic & 13.51 & 17.24 & 38.07 & 11.84 & 0.61 & 14.15 & 0.65 & 6.36 & 14.15 & 11.35 & 2.21 & 1.41 \\
\hline Denmark & 13.11 & 8.60 & 61.48 & 16.91 & 0.33 & 38.49 & 5.87 & 0.20 & 38.49 & 3.49 & 0.21 & 1.51 \\
\hline Estonia & 10.69 & 26.30 & 34.27 & 24.10 & 4.53 & 3.02 & 0.47 & 8.28 & 3.02 & 7.87 & 2.41 & 1.74 \\
\hline Finland & 17.42 & 23.13 & 29.75 & 15.53 & 3.80 & 10.65 & 0.55 & 14.13 & 10.65 & 5.67 & 0.60 & 1.74 \\
\hline France & 26.14 & 12.47 & 38.33 & 22.75 & 12.54 & 0.76 & 1.72 & 13.26 & 0.76 & 8.35 & 14.75 & 1.83 \\
\hline Germany & 12.56 & 24.42 & 29.74 & 31.95 & 2.20 & 11.52 & 0.14 & 12.88 & 11.52 & 9.85 & 1.61 & 1.91 \\
\hline Greece & 28.63 & 9.26 & 25.85 & 12.95 & 10.36 & 2.54 & 0.02 & 24.74 & 2.54 & 9.84 & 11.23 & 1.99 \\
\hline Hungary & 16.40 & 12.46 & 37.80 & 13.23 & 18.09 & 6.42 & 0.00 & 17.02 & 6.42 & 9.71 & 6.19 & 1.49 \\
\hline Iceland* & 20.18 & 25.13 & 48.56 & 18.54 & 9.01 & 14.39 & 6.32 & 2.28 & 14.39 & 3.68 & 0.78 & 1.15 \\
\hline Ireland & 16.87 & 19.79 & 41.97 & 15.65 & 16.37 & 4.81 & 5.03 & 11.30 & 4.81 & 5.63 & 3.28 & 1.09 \\
\hline Italy & 21.73 & 2.22 & 38.75 & 20.90 & 17.65 & 0.11 & 0.10 & 15.21 & 0.11 & 14.84 & 43.67 & 2.12 \\
\hline Latvia & 10.20 & 24.33 & 37.84 & 26.75 & 9.51 & 1.61 & 0.04 & 4.51 & 1.61 & 10.04 & 3.03 & 1.74 \\
\hline Lithuania & 20.90 & 10.02 & 57.42 & 25.84 & 4.93 & 24.81 & 1.87 & 6.39 & 24.81 & 5.48 & 0.49 & 1.74 \\
\hline Luxembourg & 23.66 & 11.54 & 31.32 & 13.15 & 16.74 & 0.67 & 0.82 & 21.51 & 0.67 & 10.06 & 11.29 & 1.25 \\
\hline Malta & 15.00 & 6.20 & 39.33 & 6.20 & 31.93 & 0.53 & 0.60 & 19.33 & 0.53 & 11.33 & 47.24 & 1.38 \\
\hline Netherlands & 9.06 & 26.74 & 31.80 & 13.99 & 9.46 & 5.26 & 2.91 & 0.82 & 5.26 & 10.08 & 3.52 & 1.49 \\
\hline Norway & 15.31 & 19.46 & 41.31 & 11.60 & 0.03 & 13.72 & 2.62 & 1.53 & 13.72 & 3.88 & 0.15 & 1.41 \\
\hline Poland & 16.79 & 18.83 & 34.61 & 27.03 & 6.38 & 3.90 & 0.23 & 11.20 & 3.90 & 7.43 & 7.38 & 1.38 \\
\hline Portugal & 18.89 & 6.71 & 38.26 & 14.58 & 21.66 & 0.22 & 3.19 & 15.80 & 0.22 & 15.94 & 9.25 & 1.88 \\
\hline Romania & 0.00 & 0.00 & 0.00 & 0.00 & 0.00 & 0.00 & 0.00 & 0.00 & 0.00 & 0.00 & 0.00 & 1.43 \\
\hline Slovakia & 22.83 & 9.35 & 48.22 & 15.26 & 12.68 & 20.17 & 0.16 & 11.98 & 20.17 & 8.11 & 2.05 & 1.15 \\
\hline Slovenia & 14.69 & 4.91 & 51.79 & 14.39 & 19.81 & 16.36 & 0.97 & 4.50 & 16.36 & 10.23 & 2.61 & 1.65 \\
\hline Spain & 15.81 & 4.08 & 46.75 & 20.11 & 24.31 & 0.74 & 1.51 & 13.36 & 0.74 & 14.17 & 25.85 & 1.83 \\
\hline Sweden & 14.87 & 21.60 & 45.35 & 6.78 & 1.02 & 29.66 & 7.69 & 3.21 & 29.66 & 6.75 & 0.13 & 1.66 \\
\hline United Kingdom & 13.57 & 24.49 & 38.38 & 22.18 & 5.39 & 18.71 & 5.89 & 6.07 & 18.71 & 4.74 & 0.62 & 1.56 \\
\hline Pearson $R$ & 0.028 & -0.147 & -0.083 & 0.277 & -0.004 & -0.129 & -0.213 & 0.136 & -0.129 & $\underline{0.37}$ & 0.235 & \\
\hline Pearson $P$ & 0.884 & 0.440 & 0.663 & 0.139 & 0.984 & 0.497 & 0.259 & 0.473 & 0.497 & 0.044 & 0.241 & \\
\hline
\end{tabular}

Table 2. Yearly, average antibiotic consumption for 1997-2007 expressed in percentage (\%) of the total, systemic antibiotic consumption (J01, 100\%) estimated as Defined Daily Dose/ 1000 inhabitants/ Day (DID) per country. ATC codes: J01A: tetracycline, J01C: penicillin, J01CA: broad-spectrum, beta-lactamase sensitive penicillin, J01CR: broadspectrum, beta-lactamase sensitive penicillin combined with beta-lactamase inhibitors, J01CE: narrow spectrum, penicillinase sensitive penicillin, J01CF: narrow spectrum, betalactamase resistant penicillin, J01D: cephalosporin, J01F: macrolide, J01M: quinolone, J01 $\mathrm{B} / \mathrm{N}$ : the ratio of the broad and narrow-spectrum antibiotics.

A positive correlation was observed between the consumption of quinolone (J01M) and AD prevalence ( $p: 0.044)$. 


\begin{tabular}{|c|c|c|c|c|c|c|c|c|c|c|c|c|}
\hline $\begin{array}{l}\text { Average. yearly } \\
\text { antibiotic } \\
\text { consumption } \\
\text { ECDC 2008- } \\
2018\end{array}$ & $\begin{array}{l}\text { Defined Daily } \\
\text { Dose/ 1000 } \\
\text { inhabitants/ } \\
\text { day (100\%) } \\
\text { J01 }\end{array}$ & $\begin{array}{l}\text { J01A } \\
\%\end{array}$ & $\begin{array}{l}\text { J01C } \\
\%\end{array}$ & $\begin{array}{l}\text { J01CA } \\
\%\end{array}$ & $\begin{array}{l}\text { J01CR } \\
\%\end{array}$ & $\begin{array}{l}\text { J01CE } \\
\%\end{array}$ & $\begin{array}{l}\text { J01CF } \\
\%\end{array}$ & $\begin{array}{l}\text { J01D } \\
\%\end{array}$ & $\begin{array}{l}\text { J01F } \\
\%\end{array}$ & $\begin{array}{l}\text { J01M } \\
\%\end{array}$ & $\begin{array}{l}\text { Average } \\
\text { B/N 2008- } \\
2018\end{array}$ & $\begin{array}{l}\text { Prevalence of } \\
\text { AD and other } \\
\text { dementias in } \\
\% \text { of the } \\
\text { population } \\
2018\end{array}$ \\
\hline Austria & 12.45 & 8.19 & 38.61 & 6.48 & 25.52 & 6.76 & 0.07 & 12.95 & 25.84 & 0.52 & 6.57 & 1.66 \\
\hline Belgium & 22.52 & 9.17 & 46.10 & 21.28 & 23.27 & 0.21 & 1.13 & 6.64 & 14.52 & 10.69 & 65.89 & 1.69 \\
\hline Bulgaria & 17.54 & 9.98 & 31.83 & 19.28 & 11.57 & 1.36 & 0.00 & 17.90 & 20.22 & 14.22 & 20.50 & 1.54 \\
\hline Croatia & 17.86 & 6.96 & 42.57 & 11.74 & 26.46 & 4.32 & 0.05 & 17.24 & 16.71 & 8.13 & 6.92 & 1.6 \\
\hline Cyprus & 26.77 & 12.12 & 34.94 & 10.39 & 24.35 & 0.32 & 0.09 & 21.11 & 11.50 & 16.77 & 28.19 & 1.17 \\
\hline Czech Republic & 16.51 & 13.38 & 35.88 & 7.16 & 16.67 & 11.61 & 0.23 & 10.17 & 22.04 & 6.35 & 3.95 & 1.41 \\
\hline Denmark & 15.24 & 10.75 & 63.09 & 20.54 & 4.21 & 29.46 & 8.73 & 0.21 & 13.20 & 3.26 & 0.51 & 1.51 \\
\hline Estonia & 10.23 & 16.58 & 31.73 & 17.36 & 12.38 & 2.05 & 0.01 & 10.26 & 22.84 & 8.20 & 10.83 & 1.74 \\
\hline Finland & 16.16 & 24.72 & 29.75 & 16.24 & 5.27 & 7.87 & 0.22 & 13.54 & 7.55 & 4.93 & 0.60 & 1.74 \\
\hline France & 23.62 & 13.69 & 50.54 & 29.30 & 19.30 & 0.67 & 1.17 & 9.27 & 14.74 & 7.32 & 36.42 & 1.83 \\
\hline Germany & 13.23 & 17.73 & 25.15 & 16.72 & 2.56 & 5.87 & 0.08 & 20.56 & 17.95 & 10.03 & 5.19 & 1.91 \\
\hline Greece & 32.22 & 7.42 & 29.26 & 13.66 & 14.70 & 0.87 & 0.00 & 24.53 & 26.09 & 8.12 & 242.24 & 1.99 \\
\hline Hungary & 13.65 & 8.95 & 33.95 & 7.03 & 24.39 & 2.61 & 0.00 & 14.27 & 21.67 & 15.83 & 34.17 & 1.49 \\
\hline Iceland* & 18.76 & 20.30 & 47.87 & 16.45 & 14.36 & 11.66 & 5.56 & 2.88 & 8.42 & 4.18 & 1.45 & 1.15 \\
\hline Ireland & 19.51 & 14.20 & 47.34 & 14.22 & 20.87 & 6.24 & 6.73 & 6.28 & 21.01 & 4.52 & 4.77 & 1.09 \\
\hline Italy & 22.23 & 2.41 & 45.40 & 12.90 & 31.85 & 0.00 & 0.04 & 10.68 & 20.80 & 14.67 & 141.13 & 2.12 \\
\hline Latvia & 10.75 & 21.22 & 38.21 & 26.26 & 11.51 & 0.64 & 0.01 & 5.02 & 14.45 & 9.27 & 10.05 & 1.74 \\
\hline Lithuania & 14.97 & 10.75 & 45.78 & 33.26 & 9.37 & 3.27 & 0.04 & 9.67 & 13.27 & 7.05 & 7.34 & 1.74 \\
\hline Luxembourg & 23.35 & 7.89 & 37.14 & 12.95 & 22.53 & 0.18 & 0.89 & 14.90 & 17.54 & 11.41 & 39.86 & 1.25 \\
\hline Malta & 19.18 & 6.56 & 33.08 & 2.94 & 30.15 & 0.38 & 0.24 & 23.48 & 20.52 & 23.14 & 116.99 & 1.38 \\
\hline Netherlands & 9.62 & 24.48 & 32.42 & 13.47 & 11.38 & 2.82 & 4.36 & 0.39 & 14.92 & 8.34 & 7.86 & 1.49 \\
\hline Norway & 15.28 & 19.33 & 40.04 & 13.73 & 0.04 & 22.09 & 4.00 & 0.64 & 9.98 & 3.08 & 0.19 & 1.41 \\
\hline Poland & 20.39 & 11.52 & 33.08 & 17.11 & 14.76 & 1.07 & 0.03 & 13.85 & 20.41 & 6.40 & 28.70 & 1.38 \\
\hline Portugal & 17.79 & 4.73 & 46.70 & 9.35 & 34.06 & 0.10 & 3.24 & 9.35 & 17.30 & 12.45 & 30.27 & 1.88 \\
\hline Romania & 26.14 & 3.79 & 43.56 & 16.74 & 21.42 & 2.86 & 2.41 & 17.57 & 10.62 & 12.10 & 10.64 & 1.43 \\
\hline Slovakia & 20.33 & 7.77 & 30.50 & 5.70 & 17.64 & 6.67 & 0.00 & 21.82 & 26.76 & 9.76 & 8.67 & 1.15 \\
\hline Slovenia & 11.68 & 3.00 & 59.92 & 19.39 & 24.26 & 15.04 & 1.26 & 2.99 & 16.47 & 9.46 & 2.86 & 1.65 \\
\hline Spain & 18.72 & 4.85 & 54.78 & 21.07 & 31.94 & 0.45 & 1.09 & 9.47 & 12.20 & 13.49 & 52.82 & 1.83 \\
\hline Sweden & 12.74 & 22.50 & 49.89 & 8.54 & 1.63 & 27.86 & 11.67 & 1.27 & 4.71 & 5.61 & 0.19 & 1.66 \\
\hline UK & 16.95 & 26.82 & 38.41 & 20.72 & 4.61 & 4.76 & 8.16 & 2.28 & 16.96 & 2.73 & 1.25 & 1.56 \\
\hline Pearson $R$ & -00.081 & -0.126 & 0.078 & 00.325 & 0.045 & -0.169 & -0.214 & -0.006 & 0.038 & 0.038 & 0.406 & \\
\hline Pearson $P$ & 00.673 & 0.507 & 0.681 & 0.080 & 0.813 & 0.372 & 0.256 & 0.977 & 0.843 & 0.843 & $\underline{0.026}$ & \\
\hline
\end{tabular}

Table 3. Yearly, average antibiotic consumption for 2008-2018 expressed in percentage (\%) of the total, systemic antibiotic consumption (J01, 100\%) estimated as Defined Daily Dose/ 1000 inhabitants/ Day (DID) per country. ATC codes: J01A: tetracycline, J01C: penicillin, J01CA: broad-spectrum, beta-lactamase sensitive penicillin, J01CR: broadspectrum, beta-lactamase sensitive penicillin combined with beta-lactamase inhibitors, J01CE: narrow spectrum, penicillinase sensitive penicillin, J01CF: narrow spectrum, betalactamase resistant penicillin, J01D: cephalosporin, J01F: macrolide, J01M: quinolone, J01 $\mathrm{B} / \mathrm{N}$ : the ratio of the broad and narrow-spectrum antibiotics.

A positive, strong correlation was observed between the ratios (consumption) of broad/narrow-spectrum $(\mathrm{B} / \mathrm{N})$ antibiotics and $\mathrm{AD}$ prevalence $(p: 0.026)$. Positive correlation tendency has been found between broad-spectrum, beta-lactamase sensitive penicillin (J01CA) and AD ( $p: 0.080)$. 


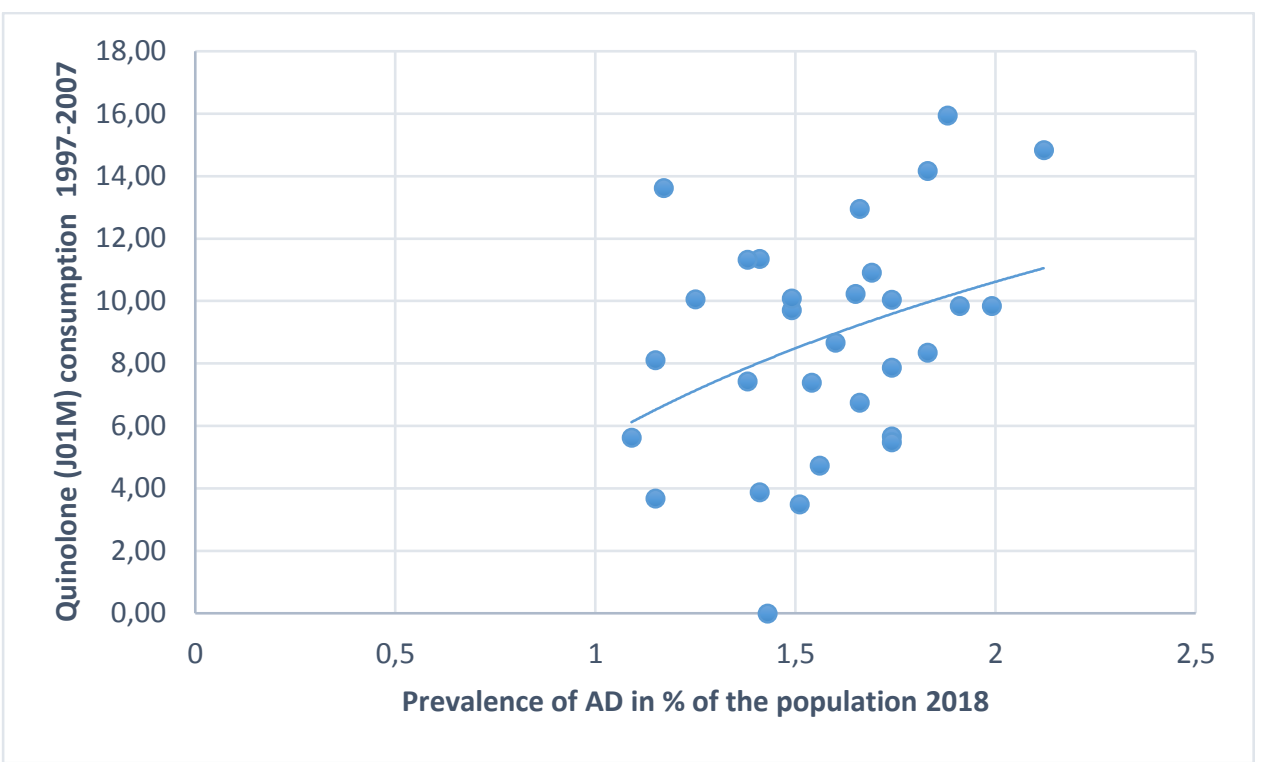

Diagram 1. Association observed between the average quinolone consumption (J01M) 1997-2007 and the prevalence of AD 2018.

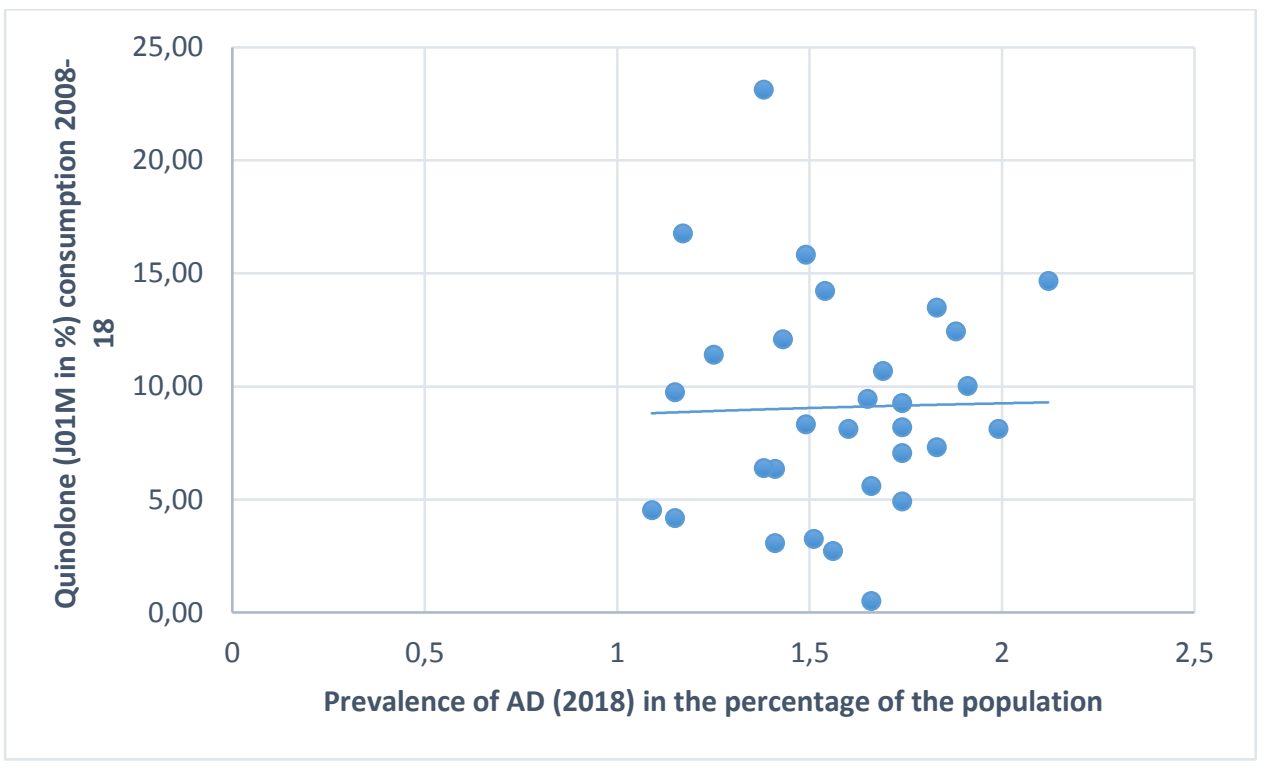

Diagram 2. No association was observed between the average quinolone consumption (J01M) 200818 and the prevalence of AD 2018. 


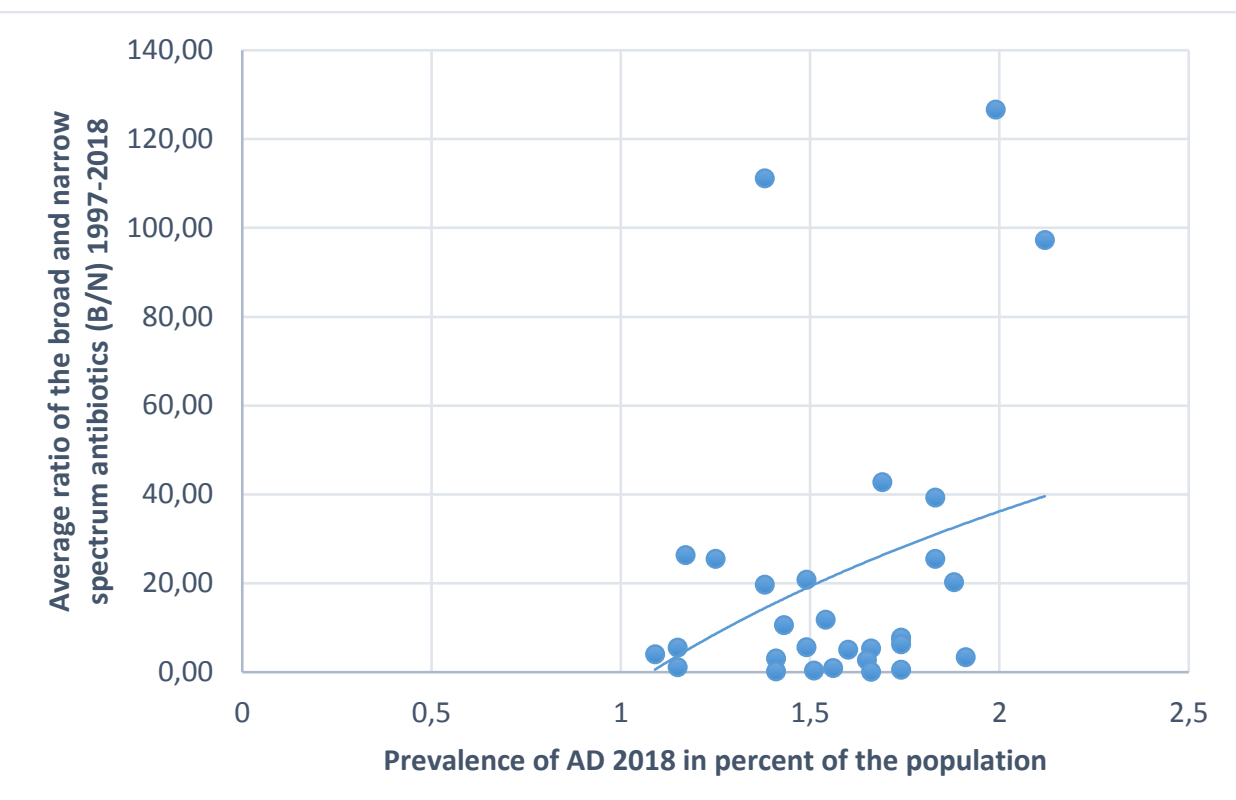

Diagram 3. A positive association was found between the AD prevalence (2018) and the high consumption ratio of broad/narrow (B/N) spectrum antibiotics 2008-2018).

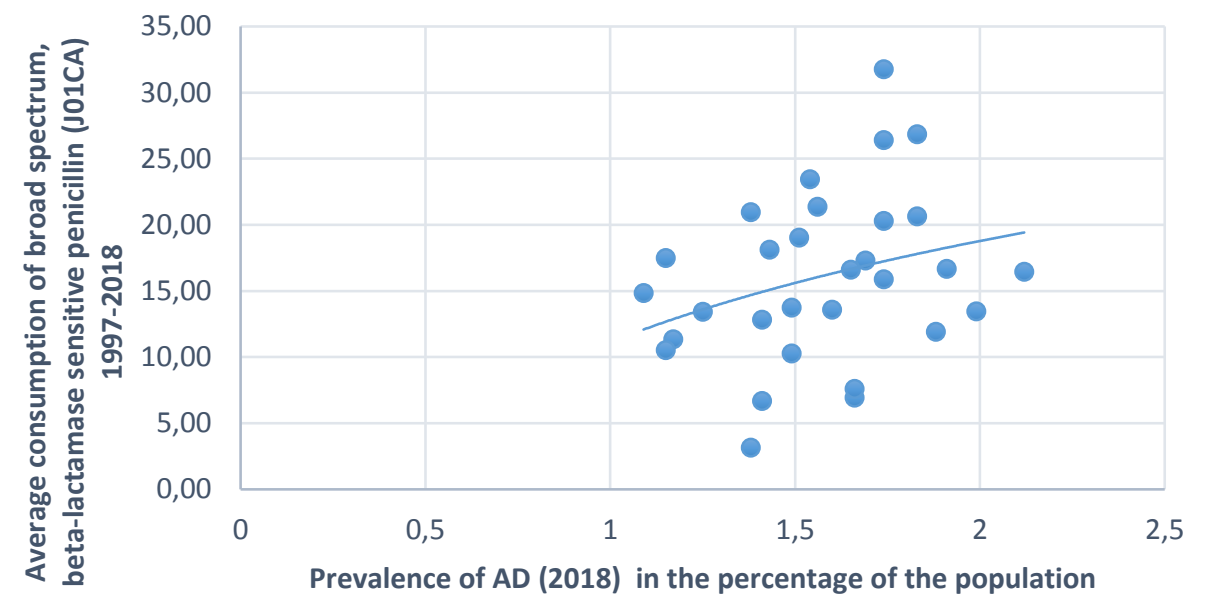

Diagram 4. A positive, moderate correlation was found between the AD prevalence (2018) and the average consumption of broad-spectrum, beta-lactamase sensitive penicillin (J01CA) 2008-2018). 


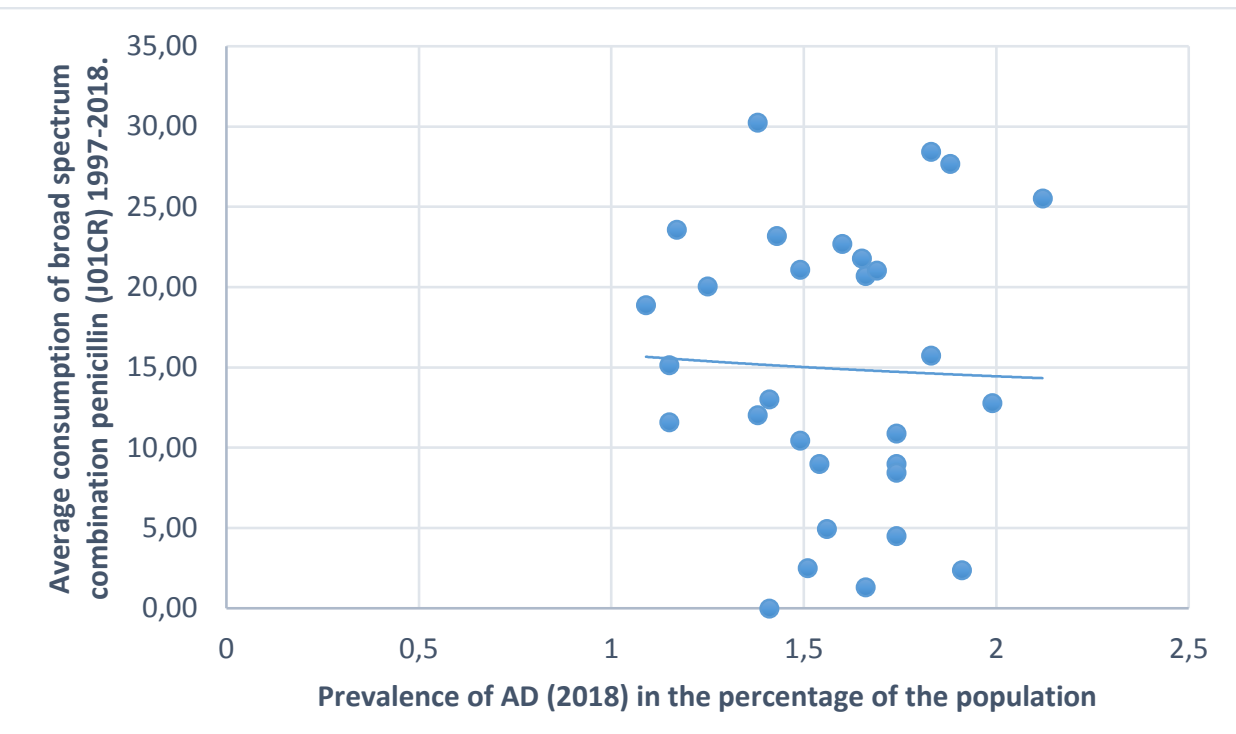

Diagram 5. No correlation was observed between the AD prevalence (2018) and the average consumption of broad-spectrum, beta-lactamase resistant combination penicillin (J01CR) 2008-2018, indicating the possible ameliorating effect of beta-lactamase inhibitors on the development of AD.

\section{Time-lapse $\mathbf{1 0 - 2 0}$ years}

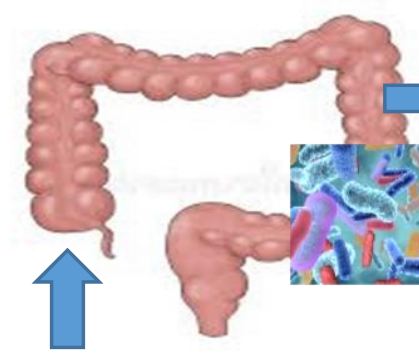

Specific classes of antibiotics producing "Alzheimer dysbiosis"

$$
\begin{aligned}
& \text { Inflammatory mediators produced } \\
& \text { by altered microbiome }
\end{aligned}
$$

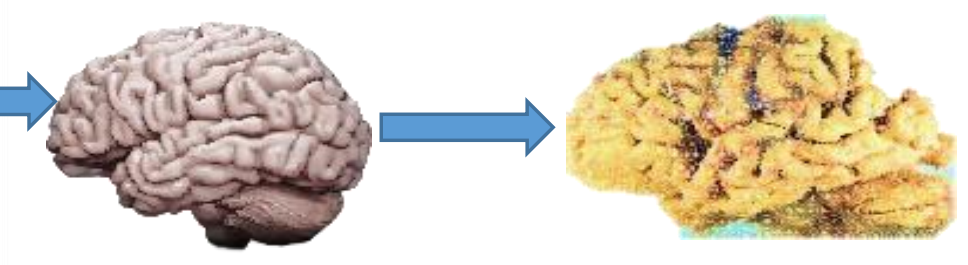

Generating amyloid depositions and $A D$ develops

Figure 1. The possible sequence of events in the development of AD

Declaration of interest: none.

This research did not receive any specific grant from funding agencies in the public, commercial, or not-for-profit sectors. 


\section{References}

1. van der Flier WM, Scheltens P (2005) Epidemiology and risk factors of dementia. J Neurol Neurosurg Psychiatry 76, (Suppl 5): v2-7.

2. Zvěřová M (2019) Clinical aspects of Alzheimer's disease. Clin Biochem 72, 3-6.

3. Zvěřová, M (2018) Alzheimer's disease and blood-based biomarkers - potential contexts of use. Neuropsychiatr Dis Treat 14, 1877-1882.

4. GBD 2016 Dementia Collaborators (2016) Global, regional, and national burden of Alzheimer's disease and other dementias, 1990-2016: a systematic analysis for the Global Burden of Disease Study. Lancet Neurol 18, 88-106.

5. Niu H, Álvarez-Álvarez I, Guillén-Grima F, Aguinaga-Ontoso I (2017) Prevalence and incidence of Alzheimer's disease in Europe: A meta-analysis. Neurologia 32, 523-532.

6. https://www.who.int/news-room/fact-sheets/detail/dementia

7. https://www.google.com/search?client=firefox-b$\mathrm{dq}=$ dementia+in+europe+yearbook +2020

8. Hardy J, Allsop D. Amyloid deposition as the central event in the etiology of Alzheimer's disease. Trends Pharmacol Sci. 1991 Oct;12(10):383-8. DOI: 10.1016/01656147(91)90609-v. PMID: 1763432.

9. Penke B, Bogár F, Fülöp L (2017) $\beta$-Amyloid and the pathomechanisms of Alzheimer's disease: a comprehensive view.Molecules (Basel Switz) 22(10):1692

10. Breijyeh Z, Karaman R. Comprehensive Review on Alzheimer's Disease: Causes and Treatment. Molecules. 2020 Dec 8;25(24):5789. doi: 10.3390/molecules25245789. PMID: 33302541; PMCID: PMC7764106.

11. Angelucci F, Cechova K, Amlerova J, Jakub H (2019) Antibiotics, gut microbiota, and Alzheimer's disease. J Neuroinflammation 16, 108

12. Jiang C, Li G, Huang P, Liu Z, Zhao B. The Gut Microbiota and Alzheimer's Disease. J Alzheimers Dis. 2017;58(1):1-15. doi: 10.3233/JAD-161141. PMID: 28372330

13. Lin L, Zheng LJ, Zhang LJ. Neuroinflammation, Gut Microbiome, and Alzheimer's Disease. Mol Neurobiol. 2018 Nov;55(11):8243-8250. doi: 10.1007/s12035-018-09832. Epub 2018 Mar 9. PMID: 29524051.

14. Sochocka M, Donskow-Łysoniewska K, Diniz BS, Kurpas D, Brzozowska E, Leszek J. The Gut Microbiome Alterations and Inflammation-Driven Pathogenesis of Alzheimer's Disease-a Critical Review. Mol Neurobiol. 2019 Mar;56(3):1841-1851. doi: 10.1007/s12035-018-1188-4. Epub 2018 Jun 23. PMID: 29936690; PMCID: PMC6394610.

15. Zhao Y, Lukiw WJ. Microbiome-generated amyloid and potential impact on amyloidogenesis in Alzheimer's disease (AD). J Nat Sci. 2015 Jul;1(7):e138. PMID: 26097896; PMCID: PMC4469284.

16. Hill JM, Bhattacharjee S, Pogue AI, Lukiw WJ. The gastrointestinal tract microbiome and potential link to Alzheimer's disease. Front Neurol. 2014 Apr 4;5:43. doi: 10.3389/fneur.2014.00043. PMID: 24772103; PMCID: PMC3983497

17. Bhattacharjee S, Lukiw WJ. Alzheimer's disease and the microbiome. Front Cell Neurosci. 2013 Sep 17;7:153. doi: 10.3389/fncel.2013.00153. PMID: 24062644; PMCID: PMC3775450.

18. Iizumi T, Battaglia T, Ruiz V, Perez Perez GI. Gut Microbiome and Antibiotics. Arch Med Res. 2017 Nov;48(8):727-734. doi: 10.1016/j.arcmed.2017.11.004. Epub 2017 Dec 6. PMID: 29221800

19. Megur A, Baltriukienė D, Bukelskienė V, Burokas A. The Microbiota-Gut-Brain Axis and Alzheimer's Disease: Neuroinflammation Is to Blame? Nutrients. 2020 Dec 24;13(1):37. doi: 10.3390/nu13010037. PMID: 33374235; PMCID: PMC7824474.

20. Panza F, Lozupone M, Solfrizzi V, Watling M, Imbimbo BP. Time to test antibacterial 
therapy in Alzheimer's disease. Brain. 2019 Oct 1;142(10):2905-2929. doi: 10.1093/brain/awz244. PMID: 31532495.

21. Minter MR, Zhang C, Leone V, Ringus DL, Zhang X, Oyler-Castrillo P, Musch MW, Liao F, Ward JF, Holtzman DM, Chang EB, Tanzi RE, Sisodia SS. Antibiotic-induced perturbations in gut microbial diversity influences neuro-inflammation and amyloidosis in a murine model of Alzheimer's disease. Sci Rep. 2016 Jul 21;6:30028. doi: 10.1038/srep30028. PMID: 27443609; PMCID: PMC4956742.

22. Zhan G, Yang N, Li S, Huang N, Fang X, Zhang J, Zhu B, Yang L, Yang C, Luo A. Abnormal gut microbiota composition contributes to cognitive dysfunction in SAMP8 mice. Aging (Albany NY). 2018 Jun 10;10(6):1257-1267. doi: 10.18632/aging.101464. PMID: 29886457; PMCID: PMC6046237.

23. Antimicrobial consumption database (ESAC-Net) - available online at https://www.ecdc.europa.eu/en/antimicrobial-consumption/surveillance-and-diseasedata/database

24. E. Rosenberg et al. (eds.), The Prokaryotes - Human Microbiology, DOI 10.1007/9783-642-30144-5_87, \# Springer-Verlag Berlin Heidelberg 2013, Sidhu M, van der Poorten D. The gut microbiome. Aust Fam Physician. 2017;46(4):206-211. PMID: 28376573.

25. Ferreira CM, Vieira AT, Vinolo MA, Oliveira FA, Curi R, Martins Fdos S. The central role of the gut microbiota in chronic inflammatory diseases. J Immunol Res. 2014;2014:689492. doi: 10.1155/2014/689492. Epub 2014 Sep 18. PMID: 25309932; PMCID: PMC4189530.

26. Lange K, Buerger M, Stallmach A, Bruns T. Effects of Antibiotics on Gut Microbiota. Dig Dis. 2016;34(3):260-8. doi: 10.1159/000443360. Epub 2016 Mar 30. PMID: 27028893

27. Haak BW, Lankelma JM, Hugenholtz F, Belzer C, de Vos WM, Wiersinga WJ. Longterm impact of oral vancomycin, ciprofloxacin and metronidazole on the gut microbiota in healthy humans. J Antimicrob Chemother. 2019 Mar 1;74(3):782-786. doi: 10.1093/jac/dky471. PMID: 30418539.

28. Zhu S, Li H, Liang J, Lv C, Zhao K, Niu M, Li Z, Zeng L, Xu K. Assessment of oral ciprofloxacin impaired gut barrier integrity on gut bacteria in mice. Int Immunopharmacol. 2020 Jun;83:106460. doi: 10.1016/j.intimp.2020.106460. Epub 2020 Apr 2. PMID: 32248021 .

29. Vogt NM, Kerby RL, Dill-McFarland KA, Harding SJ, Merluzzi AP, Johnson SC, Carlsson CM, Asthana S, Zetterberg H, Blennow K, Bendlin BB, Rey FE. Gut microbiome alterations in Alzheimer's disease. Sci Rep. 2017 Oct 19;7(1):13537. doi: 10.1038/s41598017-13601-y. PMID: 29051531; PMCID: PMC5648830.

30. Lin C, Zhao S, Zhu Y, Fan Z, Wang J, Zhang B, Chen Y. Microbiota-gut-brain axis and toll-like receptors in Alzheimer's disease. Comput Struct Biotechnol J. 2019 Oct 24;17:1309-1317. doi: 10.1016/j.csbj.2019.09.008. PMID: 31921396; PMCID: PMC6944716.

31. Serrano-Pozo A, Das S, Hyman BT. APOE and Alzheimer's disease: advances in genetics, pathophysiology, and therapeutic approaches. Lancet Neurol. 2021 Jan;20(1):68-80. doi: 10.1016/S1474-4422(20)30412-9. Erratum in: Lancet Neurol. 2021 Feb;20(2):e2. PMID: 33340485; PMCID: PMC8096522.

32. Zhu S, Li H, Liang J, Lv C, Zhao K, Niu M, Li Z, Zeng L, Xu K. Assessment of oral ciprofloxacin impaired gut barrier integrity on gut bacteria in mice. Int Immunopharmacol. 2020 Jun;83:106460. doi: 10.1016/j.intimp.2020.106460. Epub 2020 Apr 2. PMID: 32248021.

33. Sensi SL, Granzotto A, Siotto M, Squitti R (2018) Copper and Zinc Dysregulation in Alzheimer's Disease. Trends Pharmacol Sci 39, 1049-1063. 
34. Dominy SS, Lynch C, Ermini F, Benedyk M, Marczyk A, Konradi A, Nguyen M, Haditsch U, Raha D, Griffin C et al. (2019) Porphyromonas gingivalis in Alzheimer's disease brains: Evidence for disease causation and treatment with small-molecule inhibitors. Sci Adv. 23 (5), eaau3333

35. Harach T, Marungruang N, Duthilleul N, Cheatham V, Mc Coy KD, Frisoni G, Neher JJ, Fåk F, Jucker M, Lasser T et al. Reduction of Abeta amyloid pathology in APPPS1 transgenic mice in the absence of gut microbiota. Sci Rep 2017;8:41802.

36. Quigley EMM (2017) Microbiota-Brain-Gut Axis and Neurodegenerative Diseases. Curr Neurol Neurosci Rep 2017;17:94.

37. McManus RM, Heneka MT (2017) Role of neuroinflammation in neurodegeneration: new insights. Alzheimers Res Ther 2017;4:14-21.

38. Swardfager W, Lanctôt K, Rothenburg L, et al. A meta-analysis of cytokines in Alzheimer's disease. Biol Psychiatry. 2010;68:930-41.

39. Lai KSP, Liu CS, Rau A, et al. Peripheral inflammatory markers in Alzheimer's disease: a systematic review and meta-analysis of 175 studies. J Neurol Neurosurg Psychiatry. 2017;88:876-882.

40. Shen XN, Niu LD, Wang YJ, et al. Inflammatory markers in Alzheimer's disease and mild cognitive impairment: a meta-analysis and systematic review of 170 studies. J Neurol Neurosurg Psychiatry. 2019;90:590-598.

41. Balducci C, Forloni G. Doxycycline for Alzheimer's Disease: Fighting $\beta$-Amyloid Oligomers and Neuroinflammation. Front Pharmacol. 2019;10:738.

42. Balducci C, Santamaria G, La Vitola P, et al. (2018) Doxycycline counteracts neuroinflammation restoring memory in Alzheimer's disease mouse models. Neurobiol Aging 2018;70:128-139.

43. Yulug B, Hanoglu L, Kilic E, Schabitz WR. Rifampicin: an antibiotic with brainprotective function. Brain Res Bull 2014;107:37-42.

44. Moir RD, Lathe R, Tanzi RE. The antimicrobial protection hypothesis of Alzheimer's disease. Alzheimers Dement 2018;14:1602-1614.

45. Morris G, Berk M, Maes M, et al. Could Alzheimer's Disease Originate in the Periphery and If So How So? Mol Neurobiol. 2019;56:406-434.

46. Zhao Y, Jaber V, Lukiw WJ. Gastrointestinal Tract Microbiome-Derived Pro-inflammatory Neurotoxins in Alzheimer's Disease. J Aging Sci. 2021;9(Suppl 5):002.

47. Razazan A, Karunakar P, Mishra SP. Activation of Microbiota Sensing - Free Fatty Acid Receptor 2 Signaling Ameliorates Amyloid- $\beta$ Induced Neurotoxicity by Modulating Proteolysis-Senescence Axis. Front Aging Neurosci. 2021;13:735933. 
